Review of Income and Wealth

Series 64, Number 1, March 2018

DOI: $10.1111 /$ roiw. 12275

\title{
A MULTIDIMENSIONAL POVERTY INDEX FOR LATIN AMERICA
}

\author{
by Maria Emma Santos* and Pablo Villatoro \\ Instituto de Investigaciones Económicas y Sociales del Sur (IIES), Bahía Blanca, Argentina and \\ Comision Economica para America Latina y el Caribe (CEPAL), Santiago, Chile
}

This paper proposes a new Multidimensional Poverty Index for Latin America. The index combines monetary and non-monetary indicators, updates deprivation cut-offs for certain traditional unsatisfied basic needs indicators and includes some new indicators, aiming to maximize regional comparability within the data constraints. The index is estimated for 17 countries of the region at two points in time- one around 2005 and the other around 2012. Overall, we estimate about 28 percent of people are multidimensionally poor in 2012 in the region. We find statistically significant reductions of poverty in most countries, both in terms of incidence and intensity over the period under analysis. However, important disparities between rural and urban areas remain. Statistical scrutiny of the index suggests that it captures the state of poverty relatively well while maintaining a certain parsimony and being highly robust to changes in weights, indicators, and poverty cut-off.

JEL Codes: D31, I32, O54

Keywords: poverty measurement, multidimensional poverty, Latin America, Unsatisfied Basic Needs, SDGs

\section{INTRODUCTION}

The reduction of poverty is an essential aim of national public policies and international agreements. It is not only the first stand-alone Sustainable Development Goal (SDG) — as it was the first Millennium Development Goal (MDG) but also a cross-cutting one.

The multidimensionality of poverty has been acknowledged as fundamental to poverty measurement for various reasons. First, there is the recognition that new conceptual frameworks such as the rights approach and the capability approach have gained over the 1990s and 2000s, fueled by participatory studies which show that the poor describe their deprivations in terms beyond lack of income (Narayan et al., 2000; UNDP, 2013). Second, new multidimensional

Note: We are deeply grateful to Xavier Mancero and Pascual Gerstenfeld for insightful comments and suggestions throughout this research. We are also grateful to Sabina Alkire for comments and suggestions upon completion of a first draft, to Roberto Angulo Salazar and Natalie Gomez for valuable input at the beginning of this project, and to two anonymous referees for suggested changes and revisions that improved the paper. We would particularly like to acknowledge the use of the Advanced Research Computing (ARC) for intensive computations. Maria Emma Santos would like to thank ANPCyT-PICT 2015-2079 and CONICET-PIP 11220150100659CO01 for research support.

*Corresponding to: Instituto de Investigaciones Económicas y Sociales del Sur (IIES), Departamento de Economía, Universidad Nacional del Sur (UNS) - Consejo Nacional de Investigaciones Científicas y Técnicas (CONICET), San Andrés 800, 8000 Bahía Blanca, Argentinal Oxford Poverty and Human Development Initiative, University of Oxford (msantos@uns.edu.ar; maria.santos@ qeh.ox.ac.uk).

(C) 2016 International Association for Research in Income and Wealth 
poverty measurement methodologies have been developed that overcome some of the problems in aggregating different deprivations. Third, the MDGs represented an international call for a comprehensive look at deprivations in order to reveal the various aspects that are at the core of poverty. With the SDGs, this has become even more explicit in Target 1.2, which calls to "by 2030, reduce at least by half, the proportion of men, women and children of all ages living in poverty in all its dimensions according to national definitions".

So far, two levels of multidimensional poverty measures have been recently constructed. On the one hand, there is the global Multidimensional Poverty Index (MPI) (Alkire and Santos, 2010, 2014; UNDP, 2010), an internationally comparable index to measure acute poverty in the developing world in which poverty is understood as a person's inability to meet minimum international standards in indicators related to the MDGs and to core functionings. On the other hand, official national multidimensional poverty measures have been released in Mexico (CONEVAL, 2010), Colombia (Angulo et al., 2013), Chile (Ministerio de Desarrollo Social, 2015), Ecuador (Castillo Añazco y Perez, 2015), El Salvador (Gob. De El Salvador, 2015) and Costa Rica (INEC, 2015), as well as in Bhutan and The Philippines.

In this paper we attempt to cover a gap: an intermediate level between national poverty measures and international poverty ones, and thus we propose a Multidimensional Poverty Index for Latin America (MPI-LA hereafter). While national measures are relevant for the particular country in question, they are not applicable to monitoring poverty at regional level and to making cross-country comparisons. This is not a minor issue. Poverty is a key development metric and diverse actors, including governments, international development agencies, donors and the general public demand to know how different countries are performing relative to others. In fact, as currently phrased, Target 1.2 of the SDGs has the weakness of making cross-country comparisons - typically performed in the MDG Reports - very difficult: the indicators, cut-offs and weights used in national measures can differ dramatically between countries.

In turn, international poverty measures allow cross-country comparisons of widely disparate developing regions, but they fall short of accounting for what is considered to be poor in the Latin American context (Santos, 2014). In fact, Latin America is estimated to be the second least acutely poor (MPI-poor) region in the developing world (Alkire and Santos, 2014). Yet most people would agree that someone can be considered poor in the LA countries even if she is not poor according to the MPI thresholds.

The need for a Latin American MPI was expressed in Roche and Santos (2013), who explore ways in which the global MPI could be adjusted. In this paper, we take a side step from the global MPI and construct this MPI-LA by considering the dimensions and indicators that could be meaningful for the region in particular. Specifically, we follow some general guidelines offered in Santos (2014) and build upon a proposal contained in ECLAC (2013).

Santos (2014) offers an extensive review of direct measures of poverty used in the Latin American region. ECLAC (2013) presents three alternative preliminary multidimensional indices. The MPI proposed here differs from those in that it includes a tenure, a schooling gap, and an employment indicator as well as a 
different social protection indicator. It also differs in many cut-offs used, including the income one which is the income poverty line rather than the indigence line. The grouping and weighting of the included indicators is also different. Finally, Santos et al. (2010) and Battiston et al. (2013) estimated a different MPI for a reduced set of six Latin American countries. Also note that the comprehensiveness, parsimony and robustness analysis performed in this paper were not done in any of the other papers for Latin America.

It must be acknowledged that a regional index implicitly assumes some degree of cross-country homogeneity within the region in terms of what is considered to be poor or, more broadly, of the well-being function. While this is an important assumption, it is in line with what other authors have done. In fact, there is a vast literature on poverty and other subjects treating the Latin American region as a unit of analysis. Studies of this kind include the Social Panorama for Latin America annually released by ECLAC since 1991, Cardoso and Helwege (1992), the books by Attanasio and Szekely (2001), Birdsall and Garaham (2000), Lopes and Valdes (2000), and Borda and Masi (2001). ${ }^{1}$ It is also worth mentioning the more recent work by ECLAC (2010), ${ }^{2}$ Lopez-Calva and Lustig (2010) on inequality, Ferreira et al. (2012) on the middle class, Levy (2013) on social policy, Papadopoulos and Leyer (2016) on conditional cash transfers, Marinakis (2016) on minimum wages, and the Oxford Handbook of Latin American Economics (edited by Ocampo and Ros, 2012) which identifies a number of shared economic and social characteristics in the region.

Moreover, while unfortunately there has been no survey on socially perceived necessities in the region in the style of Mack and Lansley (1985), the Latinobarómetro data - an annual public opinion survey conducted in the same countries we consider in this paper-offers evidence of certain homogeneity in well-being aspirations. For example, in 2015, ten out of the 17 considered countries selected environmental issues as the first priority for development, whereas six countries selected social policies. As second and third priorities, infrastructure and social policies were the most frequently mentioned. Institutional development and international integration were most commonly set in fourth and fifth place. ${ }^{3}$ Perhaps more striking are the results of a question included in the 2007 Latinobarometro. When asked about the importance of 15 issues for feeling included in normal social life, in 16 out of 17 countries "having a respectable occupation" was selected as the most important, in 10 countries "having one's own personal income" was selected in second place and in eight "having higher education" was selected in third place.

The MPI-LA presented here draws on the rich regional tradition in poverty measurement. At the beginning of the 1980s, ECLAC introduced the Unsatisfied

\footnotetext{
${ }^{1}$ Gindling (2005) provides an excellent review of these books.

${ }^{2}$ Continuing with early analysis by Furtado (1961), Pinto (1965) and Sunkel (1970), this report refers to a structural heterogeneity that characterises Latin American economies, with a remarkable productivity gap between different sectors within each country, as well as a technological gap with respect to the international frontier.

${ }^{3}$ Also, in all 17 countries but Ecuador, more than half of the respondents thought the income distribution in their countries was either unfair or very unfair. Also, in all 17 countries but Uruguay more than half of the respondents reported to be either not at all satisfied or not very satisfied with the working of the economy.
} 
Basic Needs (UBN) method, by which the poor were identified by counting the number of deprivations they experienced (INDEC, 1984). Then, the method started to be used as a complementary method to the Poverty Line (PL) method (based on Altimir, 1979), i.e. an income poverty measure. It was understood that the PL method did not capture the satisfaction of needs that do not require spending, whereas the UBN method did not capture the needs that can be satisfied using income. Early, Beccaria and Minujin (1985) and Kaztman (1989) proposed an "integrated method" cross-tabulating the UBN poor with the income poor in a contingency table, also called the bi-dimensional method. ${ }^{4}$ But in practice, official poverty measures were kept separately.

The index innovates with respect to previous poverty measures in the region in several ways. First, its structure corresponds to the M0 measure of Alkire and Foster (2011), which satisfies convenient properties, overcoming the limitations of the headcount ratio used in the UBN method. Second, its weighting structure intends to be balanced across dimensions and indicators and it exhibits high robustness to changes. ${ }^{5}$ Third, it updates the deprivation cut-offs of the traditional UBN indicators. Fourth, it combines monetary and non-monetary indicators. Finally, it includes deprivations in the employment and social protection as well as the schooling gap. With these innovations we aim to capture not only the more acute forms of poverty, but also a "second layer" of poverty.

We estimate the MPI-LA for 17 countries at two points in time: one around 2005 and another around 2012. With this index we intend to offer an instrument for monitoring public policy and progress towards the SDGs in a cross-country comparable way, replicable over time and relevant for the Latin American population in general. However, the MPI-LA is still far from an ideal poverty measure, primarily due to data constraints. In that sense we hope that the limitations of the MPI-LA will foster improvements in data collection in the region

The paper is organized as follows. Section 2 describes the index, the data sources used, and the index's composition. Section 3 evaluates the index in terms of comprehensiveness, parsimony, and robustness. Section 4 presents the main results. Finally, Section 5 concludes. Detailed estimation results are presented as Supplementary Data.

\section{DESCRIPTION OF THE MPI-LA}

\subsection{The MPI-LA structure: The Alkire-Foster $M_{0}$ measure}

The proposed MPI-LA has the structure of Alkire and Foster (2011)'s $M_{0}$ measure, or adjusted headcount ratio. Here we briefly describe it following Alkire, Foster et al. (2015).

Let $x_{i j} \in \mathbb{R}_{+}$be the achievement of each person $i=1, \ldots, n$ in each indicator $j=1, \ldots, d$, and let $z_{j}$ be the deprivation cut-off of indicator $j$. Deprivation of person $i$ in indicator $j$ is defined as $g_{i j}^{0}=1$ when $x_{i j}<z_{j}$ and $g_{i j}^{0}=0$ otherwise. Then, the deprivation of each person is weighted by the indicator's weight, given by $w_{j}$,

\footnotetext{
${ }^{4}$ Boltvinik (1992) proposed an alternative integrated method.

${ }^{5}$ The UBN method gave equal weights across indicators, which effectively meant a disproportionate incidence of certain indicators.
} 
such that $\sum_{j} w_{j}=1$. From this, a deprivation score is computed for each person, defined as the weighted sum of deprivations $c_{i}=\sum_{j=1}^{d} w_{j} g_{i j}^{0}$. With this score the poor are identified using a second cut-off, the poverty cut-off, denoted by $k$, which represents the proportion of minimum deprivation a person must experience in order to be identified as poor. That is, someone is poor when $c_{i} \geq k$.

The deprivations of those not identified as poor are then ignored; technically, they are censored. Formally, censored deprivations are defined as $g_{i j}^{0}(k)=g_{i j}^{0}$ when $c_{i} \geq k$ and $g_{i j}^{0}(k)=0$ otherwise. Analogously, the censored deprivation score is defined as $c_{i}(k)=\sum_{j=1}^{d} w_{j} g_{i j}^{0}(k)$.

The $M_{0}$ measure combines two fundamental sub-indices: the proportion of people who are multidimensionally poor (also called poverty incidence) and their poverty intensity, given by the average (weighted) deprivations among the poor. The proportion of poor people is given by $H=q / n$, where $q$ is the number of people identified as poor. Poverty intensity is given by $A=\sum_{i=1}^{n} c_{i}(k) / q . M_{0}$, is the product of these two sub-indices:

$$
M_{0}=H \times A=\frac{1}{n} \sum_{i=1}^{n} \sum_{j=1}^{d} w_{j} g_{i j}^{0}(k)
$$

By adjusting the incidence of multidimensional poverty by the intensity, $M_{0}$ satisfies dimensional monotonicity (Alkire and Foster, 2011): if a poor person becomes deprived in an additional indicator, $M_{0}$ will increase.

Because of its additive structure, $M_{O}$ allows two types of decompositions. First, $M_{0}$ can be decomposed into population subgroups. The subgroup percentage contribution to overall poverty is the subgroup $M_{0}$ weighted by its population share, over the overall $M_{0}$. Second, after identification, $M_{0}$ can be broken down by indicator. The overall $M_{0}$ can be expressed as the weighted sum of the proportion of the total population who have been identified as poor and are deprived in each indicator (weights refer to the relative weight of each indicator). These proportions are the so-called censored headcount ratios. The percentage contribution of an indicator to overall poverty is computed as the censored headcount ratio multiplied by its relative weight, divided by the overall $M_{O}$ measure.

Last, but not least, the $M_{0}$ measure is robust to the use of ordinal variables, as it dichotomizes individuals" achievements into "deprived" and "nondeprived". This means that poverty values are not changed under changes of the variables' scales.

\subsection{Data Sources}

The data used here corresponds to the household surveys periodically performed in the countries of the region. Details of the name and survey years used are presented in Table 1. The different surveys have been harmonized by ECLAC in order to make the different variables as comparable across countries as possible. 


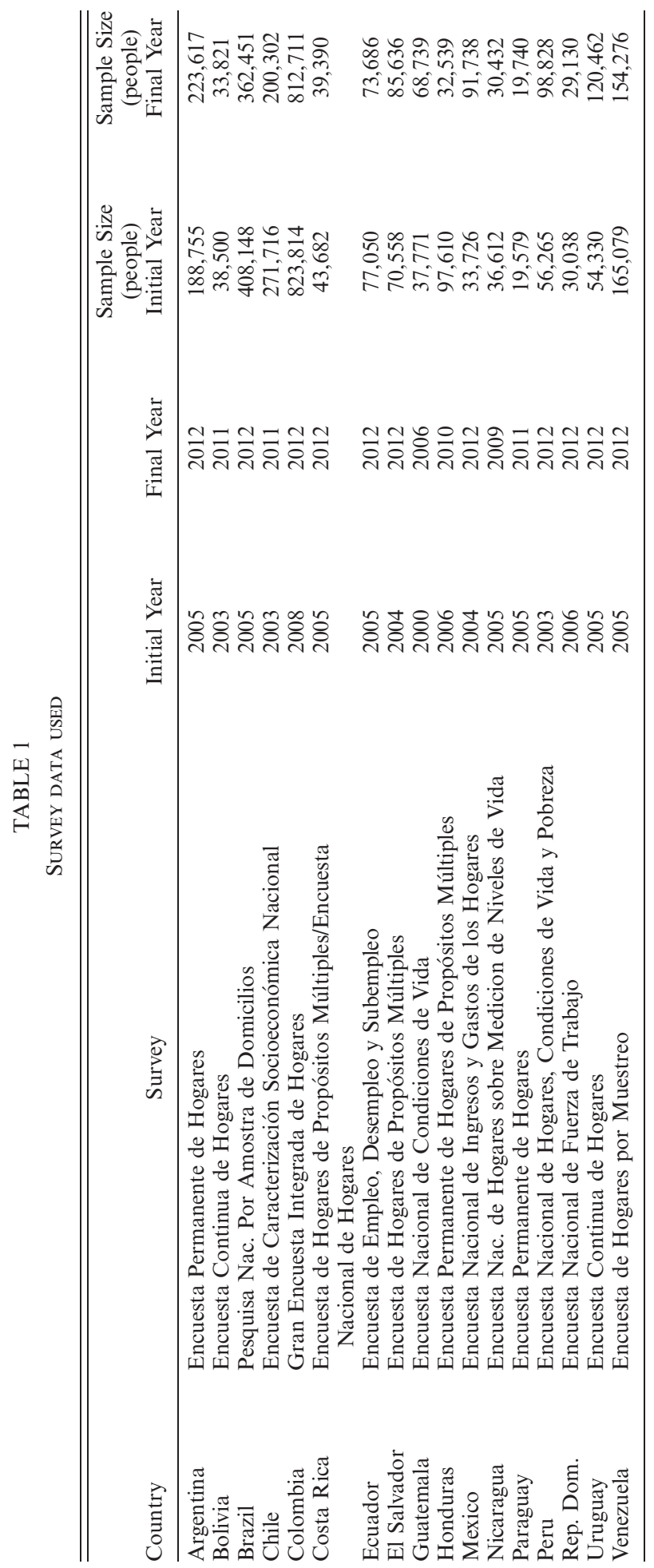

(C) 2016 International Association for Research in Income and Wealth 


\subsection{Selected Dimensions, Indicators and Cut-Offs}

The poverty index proposed here intends to maximize the available information in the current household surveys performed in the region. It is composed of 13 indicators grouped into five dimensions (see Table 2). This structure is justified on normative judgements detailed below and validated by empirical exploration of the data, comprising the implementation of factor analysis, correlation and redundancy analysis, and robustness analysis, all of which is presented in Section 3.

All indicators are defined at the household level, assuming equal sharing and externalities within the household. The unit of identification of the poor is the household and all members are considered poor if their household has been identified as such. This is a limitation imposed by the data and not exclusive to multidimensional measures (see Deaton, 1997).

The first building block of the MPI-LA is composed of a set of core deprivation indicators included in the UBN method in the region that comprise housing characteristics, basic services and two of the education indicators (adult schooling achievement and children's school attendance). All of them are well-established indicators of poverty in the Latin American context as well as globally, as they are either MDGs and/or SDGs indicators, or closely related to them. Furthermore, they are widely available in household surveys across Latin American countries.

However, given that many Latin American countries have significantly reduced the most extreme deprivations reflected in the traditional UBN indicators, we have enriched the poverty measure in three ways that we detail and justify below.

\section{Higher deprivation cut-offs for traditional UBN indicators}

We have upgraded the deprivation cut-off of the following traditional UBN indicators:

- Overcrowding indicator: from more than three people per room to three or more people per room, a criterion used in the overcrowding indicator complementary to the MDGs' indicators. This is an intermediate criterion between the one used in Chile and Mexico (2.5 or more people per room) and the historical one still being used in other countries.

- Safe drinking water: In urban areas, it is required to have pipe in the dwelling or to the yard plot, or a protected well with pump water in order to be non-deprived (whereas, previously, piped water outside the yard was considered non-deprived). In rural areas, access to a public tap is also considered to be non-deprived.

- Improved sanitation: Following the MDGs, households sharing their sanitation facility with other households are now considered to be deprived.

- Children's school attendance: Households are deprived if there is at least one child or adolescent between six and 17 years of age (before it was between six and 14 years) who is not attending school. Households without children are considered non-deprived in this indicator. This is in line with changes in the legislation in several countries, which have extended mandatory schooling up to secondary school. 
TABLE 2

MPI-AL: SELECTED DIMENSIONS, DEPRIVATION INDICATORS AND WEIGHTS

\begin{tabular}{|c|c|c|}
\hline Dimensions & Deprivation Indicators: People Who Live In... & $\begin{array}{l}\text { Weights } \\
(\%)\end{array}$ \\
\hline Housing & & 22,2 \\
\hline Housing materials ${ }^{a}$ & $\begin{array}{l}\text { Households with dirt floor or precarious roof or } \\
\text { wall materials (waste, cardboard, tin, cane, } \\
\text { palm, straw, other materials). }\end{array}$ & 7,4 \\
\hline People per room ${ }^{b}$ & $\begin{array}{l}\text { Households with three or more people per room, } \\
\text { in urban and rural areas (overcrowding). }\end{array}$ & 7,4 \\
\hline Housing tenure $\mathrm{c}$ & $\begin{array}{l}\text { Households which live in i) an illegally occupied } \\
\text { house or ii) in a ceded or borrowed house }\end{array}$ & 7,4 \\
\hline Basic Services & & 22,2 \\
\hline Improved Water & Urban areas: & 7,4 \\
\hline Source $^{\mathrm{d}}$ & $\begin{array}{l}\text { Households with some of the following water } \\
\text { sources: } \\
\text { - piped to yard/plot; } \\
\text { - unprotected well or without mechanic pump; } \\
\text { - cart with small tank; } \\
\text { - bottled water; } \\
\text { - river, spring, dam, lake, ponds, stream, rain- } \\
\text { water, other. } \\
\text { Rural areas: } \\
\text { Households with some of the following water } \\
\text { sources: } \\
\text { - unprotected well or without mechanic pump; } \\
\text { - cart with small tank; } \\
\text { - bottled water; } \\
\text { - river, spring, dam, lake, ponds, stream, rain- } \\
\text { water, other. }\end{array}$ & \\
\hline Improved Sanitation $^{\mathrm{d}}$ & $\begin{array}{l}\text { Urban areas: } \\
\text { Households with some of the following: } \\
\text { - toilet or latrine not connected to piped sewer } \\
\text { system or septic tank; } \\
\text { - shared toilet facility; } \\
\text { - no toilet facility (bush/field). } \\
\text { Rural areas: } \\
\text { Households with some of the following: } \\
\text { - no toilet facility (bush/field); } \\
\text { - shared toilet facility; toilet or latrine flushed } \\
\text { without treatment to surface, river or sea. }\end{array}$ & 7,4 \\
\hline Energy ${ }^{\mathrm{e}}$ & $\begin{array}{l}\text { Households with no access to electricity or which } \\
\text { use wood, coal or dung as cooking fuel. }\end{array}$ & 7,4 \\
\hline Living Standard & & 22,2 \\
\hline Monetary Resources & $\begin{array}{l}\text { Households with insufficient per capita income to } \\
\text { cover food and non-food needs. }\end{array}$ & 14,8 \\
\hline Durable Goods ${ }^{\mathrm{f}}$ & $\begin{array}{l}\text { Households which do not own any of the follow- } \\
\text { ing items: car, refrigerator or washing machine. }\end{array}$ & 7,4 \\
\hline Education & & 22,2 \\
\hline $\begin{array}{l}\text { Children's School } \\
\text { Attendance }\end{array}$ & $\begin{array}{l}\text { Households where there is at least one child or } \\
\text { adolescent ( } 6 \text { to } 17 \text { years) not attending school. }\end{array}$ & 7,4 \\
\hline Schooling Gap & $\begin{array}{l}\text { Households where there is at least one child or adoles- } \\
\text { cent ( } 6 \text { to } 17 \text { years) who is over two years delayed } \\
\text { with respect to his/her schooling grade for age. }\end{array}$ & 7,4 \\
\hline $\begin{array}{l}\text { Adult } \\
\text { Schooling Achievement }\end{array}$ & $\begin{array}{l}\text { Households where no member } 20 \text { years or older has } \\
\text { achieved a minimum schooling level, defined as: } \\
\text { - complete lower secondary school for people } \\
\text { between } 20 \text { and } 59 \text { years, and } \\
\text { - complete primary school for people of } 60 \text { years } \\
\text { or more. }\end{array}$ & 7,4 \\
\hline
\end{tabular}


Table 2 Continued

\begin{tabular}{|c|c|c|}
\hline Dimensions & Deprivation Indicators: People Who Live In... & $\begin{array}{c}\text { Weights } \\
(\%)\end{array}$ \\
\hline \multicolumn{2}{|c|}{ Employment and Social Protection } & 11,1 \\
\hline Employment & $\begin{array}{l}\text { Households with at least one member between } 15 \\
\text { and } 65 \text { years old being one of the following: } \\
\text { - unemployed; } \\
\text { - employed without a pay; or } \\
\text { - a discouraged worker. }\end{array}$ & 7,4 \\
\hline Social Protection ${ }^{g}$ & $\begin{array}{l}\text { Households experiencing at least one of the fol- } \\
\text { lowing characteristics: } \\
\text { - no member has some form of contributory } \\
\text { health insurance; } \\
\text { - no member is contributing to a social security } \\
\text { system and no member is receiving a pension or } \\
\text { retirement income. }\end{array}$ & 3,7 \\
\hline
\end{tabular}

${ }^{\text {a }}$ There was no available information on the following items for the following countries and years: walls for Argentina (2005, 2012), floor for Brazil (2005, 2012), roof for Colombia (2008, 2012) and Ecuador (2005), housing materials for Uruguay (2005). See details of surveys used in Table 1.

${ }^{\mathrm{b}}$ Given that in the case of Brazil, Costa Rica, Honduras and Mexico, the number of rooms does not exclude kitchen and/or toilets, we corrected the number of rooms in the house using Kaztman's (2011) suggestion of subtracting one from the total number of rooms.

${ }^{\mathrm{c}}$ Households living in houses given in usufruct were not considered as deprived.

${ }^{\mathrm{d}}$ In the case of the Dominican Republic (2006 and 2012), we applied the same deprivation definition for urban areas to rural ones because the survey question does not allow us to differentiate between the two.

${ }^{\mathrm{e}}$ There is no information on access to electricity for Argentina (2005 and 2012), the Dominican Republic (2006) and Uruguay (2005); and there is no information on cooking fuel for Chile (2003 and 2011), Honduras (2006) and Venezuela (2005 and 2012).

${ }_{\mathrm{f}}^{\mathrm{f}}$ There is no information on durable goods for Argentina (2005 and 2012) and Bolivia (2003). There is no information on car ownership for Brazil (2005) and Chile (2003), thus it has been replaced by ownership of a stove and ownership of a water boiler correspondingly. There is no information on washing machines for Costa Rica (2012) and Honduras (2010 and 2006), and it has been replaced by a TV with plasma or LCD screen for Costa Rica and a heater for Honduras.

${ }^{\mathrm{g}}$ There is no information on health insurance for Brazil (2005 and 2012) and Venezuela (2005 and 2012). The indicator on social protection has not been included for Nicaragua (2009) because of lack of information on both sub-indicators (social security system and health insurance).

- Adult schooling: we require lower secondary school completion for people between 20 and 59 years of age, and we leave the (traditional) primary school completion requirement for people of 60 years or more. This is more consistent with the number of years of education currently necessary to improve the probability of accessing a decent job and income and being integrated into society (Villatoro, 2007).

\section{Including income alongside non-monetary indicators}

There are two arguments frequently offered to justify the practice of keeping the monetary poverty and UBN measures separate. The first argument is that each of these measures captures different aspects of poverty. The UBN measure would mainly capture deprivation in access to public services and income poverty would capture insufficient resources to satisfy needs through the market. 
However, this distinction does not actually hold in the current Latin American context. The typical non-monetary deprivations used in the UBN measurewater and sanitation, electricity and gas, education and housing - are no longer provided (and highly subsidized) by the State as it used to be in the 1980s, but rather subject to the market rules. In fact, the results of factor analysis presented in Section 3 do not support the distinction between monetary and non-monetary poverty; on the contrary, results suggest that while income provides very relevant information, it is insufficient as a standalone measure

The second argument is that because income is a fungible resource, it can be used to satisfy a variety of needs, including those considered in the non-monetary indicators. Thus, income would be at risk of being redundant. Yet, redundancy analysis presented in Section 3.2 does not support this view. Moreover, not every time two indicators appear to be redundant should one be dropped; normative reasons as well as the information they can provide for public policy can be good reasons to keep both. In our case, the income deprivation indicator offers valuable information for public policy design, such as conditional cash transfer programs.

Thus, both arguments most commonly given to keep the income poverty measure and the UBN measure separate are weak and not empirically verified. On the contrary, combining income with the non-monetary indicators in the multidimensional poverty measure has several advantages. In fact, such practice has recently been proposed in diverse contexts (see Callan, Nolan and Whelan, 1993, and Nolan and Whelan, 1996 for the Irish case, Bradshaw and Finch, 2003, and Alkire, Apablaza and Jung, 2014 for the European Union case, Santos et al., 2010 and ECLAC, 2013 for Latin American countries; also see Alcock, 2006 and Nolan and Whelan, 2011 for further conceptual discussion). ${ }^{6}$ We have followed that route here. Empirically, evidence presented in Sections 3 and 4 supports this decision. Additionally, in the regional, limited data context, income can act as a surrogate - even if imperfectlyfor some missing dimensions, such as nutrition and health. Income can also complement the information provided in the included non-monetary indicators, especially when such indicators are limited or likely to have measurement error.

Note that we use ECLAC's income indicator by which the income deprived are identified considering the household per capita income. ${ }^{7}$ ECLAC calculates poverty lines that aim for regional comparability, using the cost of basic needs method. We have used the total poverty line (including food and non-food items) as the deprivation cut-off of the income indicator rather than the indigence line. Conceptually, the total poverty line provides a more complete basis for identifying the poor than the indigence line, which only considers food items. Empirically, the proportion of indigent people in each country is relatively low, resulting in a limited scope when using the indigence line. ${ }^{8}$

\footnotetext{
${ }^{6}$ The national measures of Mexico and Chile include income and consider someone as multidimensionally poor if she is income poor and deprived in non-monetary indicators. The Colombian measures keeps income poverty as a separate measure.

${ }^{7} \mathrm{An}$ alternative procedure is to use the household equivalent income. While this has advantages, we use ECLAC's indicator for a better comparability between traditional income poverty estimates in the region and the proposed MPI-LA, as performed in Section 4.4.

${ }^{8}$ The proportion of people under the indigence line varies from 1 percent to 49 percent and it is on (simple) average 17 percent, whereas the proportion of people under the total poverty line varies from 4 percent to 71 percent, and it is on (simple) average 38 percent.
} 
Including new non-monetary indicators: Finally, we have incorporated two types of non-monetary indicators of poverty. On the one hand, based on the available data, we included three deprivation indicators of arguably basic needs that complement the usual UBN indicators. First, we include an indicator of insecure housing tenure (within the housing dimension). A tenure arrangement, which protects against forced eviction and other threats, has been recognized as a component of the right to an adequate living standard (UN, 2009). Second, we include an indicator of energy deprivation (within the basic services dimension aligned with indicators of the MDGs and SDGs (Goal 7). Third, we include deprivation of durable goods as a proxy of a permanent living standard.

On the other hand, a novelty of this MPI-LA is that we incorporated a set of indicators that aim to reflect precarious linkages with institutions. This implies broadening the criteria of poverty identification, including deprivations that reflect relative disadvantage alongside the more extreme deprivations.

Considering what is available across the surveys, we have included an indicator of deprivation in employment based on its intrinsic importance and its implications for social integration (Atkinson, 2002). The International Labor Organization (ILO) has claimed labor to be a source of dignity, security, family stability and social peace, and the SDGs (Goal 8) echo this. We considered households to be deprived in employment when there is at least one member who is (i) unemployed, (ii) employed without a pay, or (iii) discouraged worker.

In turn, access to social protection is a fundamental human right and part of ILO's decent work agenda. We have incorporated a union indicator by which a household is considered deprived if no member has some form of contributory health insurance or if no member has some form of contributory retirement (either mandatory or voluntary) and no elderly member is receiving some pension or retirement income.

It must be noted that until mid-2000s official measures of poverty in the region did not include employment and social protection indicators. It can be claimed that these dimensions were not part of the notion of poverty prevalent among the institutional actors. Yet, over the last seven years several countries of the region-Mexico, Colombia, Chile, El Salvador, Costa Rica and Ecuadorhave included these kind of indicators in their official poverty measures. Here we join this practice under the argument that these deprivations are an expression of a new type of poverty in the region. In fact, it has been claimed that the privatization of public services in the decades of 1980s and 1990s deepened the quality gap in the provision of education, health and pensions received by the different socioeconomics groups, deteriorating disadvantaged groups and creating a strong perception of relative deprivation among them (Kaztman, 2001, 2010). This is reinforced by labor market segmentation, which translates into the poor accessing precarious jobs with non-existent or deficient social protection (Kaztman, 2010). Departing from what has been done in the official measures of the cited countries however, the cut-off used for the social protection indicators is to have access to contributive social protection. We selected this more demanding cut-off than 
simple access, (a) to improve cross-country comparability and (b) in order to have a proxy of the quality of social protection. ${ }^{9}$

We have also included an indicator of schooling gap. ${ }^{10}$ Given that there has been a significant increase in the coverage of primary and secondary school in the region (ECOSOC, 2011), focus is progressively shifting from schooling coverage to educational quality, where variability is highly associated with the socioeconomic intake of schools. Although imperfect, the schooling gap indicator offers a proxy for the quality of education children receive. In fact, there is evidence that entering school after the compulsory age, as well as repetition of grades, is likely to be a sign of deprivation-leading to drop-outs and underperformance (ECOSOC, 2011; UNESCO, 2012).

\subsection{Limitations of the MPI-LA and improvements in data collection}

The proposed MPI-LA has several limitations due to data constraints. First, estimates are not fully comparable because not all surveys with the information on the MPI-LA indicators were collected for the same years (see Table 1). There are still many countries where surveys depend on the availability of resources and are collected with a low frequency. Second, there are dimensions that we would have liked to include and could not due to data limitations, such as health. We were only able to include access to (a contributory) health insurance. Indicators on fundamental cognitive skills, employment formality and quality are other important missing indicators. Even the data collection on income information, housing, basic services and ownership of durable goods requires further harmonization and improvements.

Additionally, promoting the inclusion of questions on socially perceived necessities in the European style (Mack and Lansley, 1985; Nolan and Whelan, 2011) would contribute to validate regional as well as national poverty measures.

In sum, although there have been significant improvements in terms of data collection in the region, there are still many not necessarily costly ways in which survey data collection could be improved - which would allow overcoming many of the current limitations of the proposed MPI-LA.

\subsection{Weighting Structure and the Poverty Cut-Off}

Weights in multidimensional indices are typically a critical point of controversy as there is no widely accepted theoretical framework that allows deciding a priori whether one weighting structure is better than another. However, this need not impede the evaluation of injustice or the design of public policy (Sen, 2009, p. 243). A range of weights over which there is some agreement and which yields rather similar principal guidelines can be operationally

\footnotetext{
${ }^{9}$ For further details in terms of the comparability of access to social protection indicator, see ECLAC (2014).

${ }^{10}$ This indicator has been included in the official measures of Mexico and Colombia. We have used "two years delayed" for the indicator because a threshold of one year could be misleading given the different school calendars, effective age of entrance to school and time of the year in which each survey is conducted.
} 
sufficient. ${ }^{11}$ On these lines, it has been suggested that researchers need to rely on common sense and robustness analysis (Decancq and Lugo, 2012). This is precisely the route we have followed.

Table 2 presents the selected weighting structure. The housing, basic services, living standard and education dimensions are equally weighted with 22.22 percent, whereas the social protection dimension receives half of this weight, 11.11 percent. In turn, weights within dimensions are equally distributed in the case of the housing, basic services and education dimensions, and unequal within the living standard and the social protection dimensions, with income and employment receiving twice the weight of durable goods and social protection within the corresponding dimensions. As a result, all deprivations receive the same weight (7.4 percent) except for social protection (3.4 percent) and income (14.8 percent).

The rationale for weighting the employment and social protection dimension with half the weight of the other four dimensions is twofold. On the one hand, as explained in Section 2.3, the deprivations contained in this dimension go a step beyond the traditional conception of poverty in the region. Second, the effective weighting of a dimension is a result of the explicit weight and the deprivation cutoffs used. Deprivation rates in employment and social protection tend to be high under the demanding cut-offs used. Thus, we implemented the not uncommon practice of weighting less the more widespread deprivations; the implicit assumption is that individuals tend to attribute more importance to less prevalent deprivations (see Desai and Shah, 1988; Decancq and Lugo, 2012). The whole employment and social protection dimension receives half the weight of the other dimensions, and-within it - the social protection indicator receives half the weight of the employment one.

In turn, there are two reasons for weighting the income indicator with twice the weight as the durable goods one within the living standard dimension. First, in highly mercantile economies, as it is the case of Latin American countries where the State provides a very limited number of public goods for free, income has an important role in satisfying needs. Second, income is a synthetic indicator serving as a surrogate for deprivations which could not be included and as a complement of some of the included ones. It must be noted that whenever an indicator is missing in a country, weights are equally distributed among the observed indicators. Such cases are detailed in the note of Table 1.

While we favor the described weighting structure, we have performed two kinds of robustness tests that are detailed in Section 4.3. We have found that the MPI-LA is robust to the weights used.

In terms of the poverty cut-off, the preferred $k$ value is 25 percent, i.e. a quarter of the total weighted indicators. This means that in order to be identified as poor a person must experience deprivations in the equivalent of a full dimension of housing, services, education or living standard, plus some other indicator, or,

${ }^{11}$ Additionally, as explained in Alkire et al. (2015), it must be noted that weights in the $M_{0}$ measure used in this paper, which is based on dichotomized deprivations, reflect the relative impact that the presence or absence of a deprivation has on the person's deprivation score. They do not govern trade-offs across different levels of achievement in different variables, as it is the case in measures based on cardinal variables using normalized gaps for example. This feature makes the selection of weights somehow less critical. 
alternatively, they must be deprived in income and two additional indicators. In other words, with this cut-off, the poor are truly multidimensionally poor as deprivation in any full dimension is not enough. However, as with weights, we computed the MPI-LA (as well as many other alternative specifications) for a range of $k$ values, from 10 percent (just above a union criterion) to 100 percent (intersection criterion). ${ }^{12}$ As presented in Section 4.3, we found the MPI-LA to be highly robust to a restricted plausible range of poverty cut-offs.

\section{Comprehensiveness, Parsimony and Robustness of the MPI-LA}

We have evaluated whether the proposed multidimensional poverty index complies with three desirable characteristics: comprehensiveness, parsimony, and robustness. We present each analysis in turn. These statistical analysis may be understood as a form of validation of the normatively motivated index.

\subsection{Comprehensiveness}

By comprehensiveness we mean that the index should capture poverty in the region, including, as much as possible, the deprivations that are widely recognized as constituent elements of poverty. Of course, comprehensiveness is restricted by data availability. Thus, while no poverty measure will ever capture all the relevant deprivations, at least we intend to include those that - being available - are relevant. Ideally, this would rely on a survey on socially perceived necessities (Mack and Lansley, 1985). Given that we do not count with such type of surveys in the region, we need to rely on other forms of validation of the dimensions and indicators included.

In the first place, we build upon a thorough review provided in Santos (2014) and also considered by ECLAC (2013) of the rich experience in the Latin American region in multidimensional poverty measurement, as well as of the European tradition. We also draw from the literature on global poverty. The dimensions and indicators contained in the proposed MPI-LA have been previously used and are normatively justified as relevant for poverty either regionally or by the international literature.

In the second place, we have performed an exploratory factor analysis (EFA) in order to verify the empirical relevance of the indicators as indicators of poverty, complementing the normative arguments. ${ }^{13}$ Assuming a bivariate normal distribution, Table 3 presents a summary of the exploratory factor analysis results using tetrachoric correlations, given that all our indicators are dichotomous. ${ }^{14}$ It reports a simple average across observations of the factor loadings of each

\footnotetext{
${ }^{12} \mathrm{~A}$ union criterion requires a person to experience any deprivation in order to be considered poor.

${ }^{13}$ We implemented EFA rather than Principal Components Analysis (PCA) because EFA aims to reveal any latent variables that cause the observed variables to co-vary, whereas PCA is computed without regard to any underlying structure caused by latent variables (Costello and Osborne, 2005).

${ }^{14}$ Factor analysis procedures produce valid results only if the data are truly continuous and multivariate normal. Clearly, this is not the case of dichotomous variables. We used the factormat command in Stata. With this, the EFA is performed using the matrix of tetrachoric correlations as the input, rather than the raw variables.
} 
A final remark is that the EFA results do not suggest different groups of indicators, such as UBN vs. income, loading on different factors. This suggests that the sometimes argued position that UBN indicators account for a different kind of poverty than income poverty does not seem to hold.

In sum, considering well-established normative arguments provided by the literature combined with empirical analysis, the proposed MPI-LA seems to be comprehensive given the current data limitations.

\subsection{Parsimony}

By parsimony we mean that, while capturing poverty as well as possible, the MPI-LA is also kept as simple as possible, avoiding potential redundancy between indicators. However, the fact that two deprivations tend to occur simultaneously in one period does not necessarily indicate redundancy. On the contrary, accounting for the joint distribution of deprivations is at the core of multidimensional poverty measurement. In other words, evaluating potential redundancy is far from a mechanical matter, and one needs to carefully scrutinize the numbers and consider not only empirical but also normative arguments.

In order to explore potential redundancies between the indicators we computed two measures, as suggested by Alkire et al. (2015, Ch. 7). ${ }^{16}$ One of them is the Cramer V correlation coefficient between all pairs of deprivation indicators. Given two deprivation indicators, $j$ and $j^{\prime}$, this coefficient uses the information contained in a cross tabulation, such that

$$
\text { Cramer's } V=\frac{\left(\mathbb{P}_{00}^{i j^{\prime}} \times \mathbb{p}_{11}^{i j^{\prime}}\right)-\left(\mathbb{P}_{10}^{i j^{\prime}} \times \mathbb{p}_{01}^{j j^{\prime}}\right)}{\left[\mathbb{P}_{+1}^{j^{\prime}} \times \mathbb{p}_{1+}^{j} \times \mathbb{p}_{+0}^{j^{\prime}} \times \mathbb{p}_{0+}^{j}\right]^{1 / 2}},
$$

where $\mathbb{P}_{00}^{j j^{\prime}}$ is the proportion of people non-deprived in both $j$ and $j^{\prime}, \mathbb{P}_{11}^{j j^{\prime}}$ is the proportion of the people deprived in both $j$ and $j^{\prime}, \mathbb{p}_{10}^{i j^{\prime}}$ is the proportion of people deprived in $j$ but not in $j^{\prime}$, and $\mathbb{p}_{01}^{i j^{\prime}}$ is the proportion of people deprived in $j^{\prime}$ but not in $j . \mathbb{p}_{+1}^{j^{\prime}}$ and $\mathbb{p}_{1+}^{j}$ are the proportions of people deprived in $j^{\prime}$ and $j$ correspondingly, whereas $\mathbb{p}_{+0}^{j^{\prime}}$ and $\mathbb{p}_{0+}^{j}$ are the proportions of people non-deprived in $j^{\prime}$ and $j$ correspondingly.

The other measure has been proposed by Alkire and Ballon (2012) as a measure of redundancy $R^{o}$. This measure shows the matches between deprivations as a proportion of the minimum of the marginal deprivation rates, and it is defined as

$$
R^{o}=\mathbb{p}_{11}^{i j^{\prime}} / \min \left(\mathbb{P}_{+1}^{j^{\prime}}, \mathbb{p}_{1+}^{j}\right), 0 \leq R^{o} \leq 1
$$

That is, the measure of redundancy displays the number of observations that have the same deprivation status in both variables, which reflects the joint distribution, as a proportion of the minimum of the two uncensored or censored headcount

\footnotetext{
${ }^{16}$ The notation used here borrows from the cited source.
} 
ratios. ${ }^{17}$ In this paper we use the uncensored headcount ratios. $R^{o}$ offers complementary information to correlation because it accounts for the overall level of deprivation in the indicator with the lowest deprivation.

Table 4 presents a summary of the results of the two measures detailed above. It reports the simple average across the 34 observations alongside the minimum and maximum values of the Cramer $\mathrm{V}$ and $\mathrm{R}$ measures between indicators within each dimension and between each indicator and income. It can be observed that on average - both the correlation and the redundancy measures are low between indicators within each dimension. Results of the average Cramer V indicate that correlation is higher between housing materials and overcrowding, water and sanitation, and water and energy, but the average coefficient is never above 0.24. In turn, the $R^{o}$ measure suggests higher potential redundancy within the education dimension and the employment and social protection dimension. Yet, even for the pairs of indicators in those dimensions, the average $R^{o}$ coeficient is 0.67 at most, indicating that one in three persons (living in a household) deprived in one of the indicators (say, adult schooling) is not deprived (the household is not deprived) in the other (say, children's school attendance). In addition, the range is high with only 22 percent of persons deprived in adult schooling being deprived in school attendance in some countries. Thus, dropping one of the two indicators within the dimension would increase the probability of missidentifying the poor.

The correlation and redundancy results for income paired with each of the other indicators offer similar conclusions. The Cramer V between monetary and non-monetary deprivations is below 0.25 in most cases. The lowest average correlations are with tenure (0.08), followed by children's school attendance $(0.15)$ and schooling gap (0.16), whereas the highest average correlations are with durable goods $(0.25)$ and social protection $(0.33)$. Also, while the average $R^{o}$ coeficients between income and the non-monetary deprivation indicators are higher than between the non-monetary indicators within each dimension, the highest are 0.75 (between income and social protection) and 0.67 (between income and durable goods). Even these apparently high redundancy values are not really so, as they indicate that one in four people deprived in, say, income, are not deprived in social protection. Furthermore, again the range is large, with less than half of those deprived in income being deprived in social protection in some contexts. Thus, as argued above, dropping one of the two indicators, would negatively affect the capacity of the MPI-LA to identify the poor in each country.

It must be noted however that the estimation of these measures did lead us to collapse the access to health care indicator and the social security one into a combined union indicator of social protection. The redundancy measure between these two indicators was above 0.90 .

\subsection{Robustness}

Finally, when deciding on a particular index it is fundamental to have a sense of the robustness of the index to changes in the parameters, especially if the index

\footnotetext{
${ }^{17} \mathrm{By}$ using the minimum of the uncensored or censored headcounts in the denominator it is ensured that the maximum value of $R^{0}$ is 100 percent.
}

(C) 2016 International Association for Research in Income and Wealth 


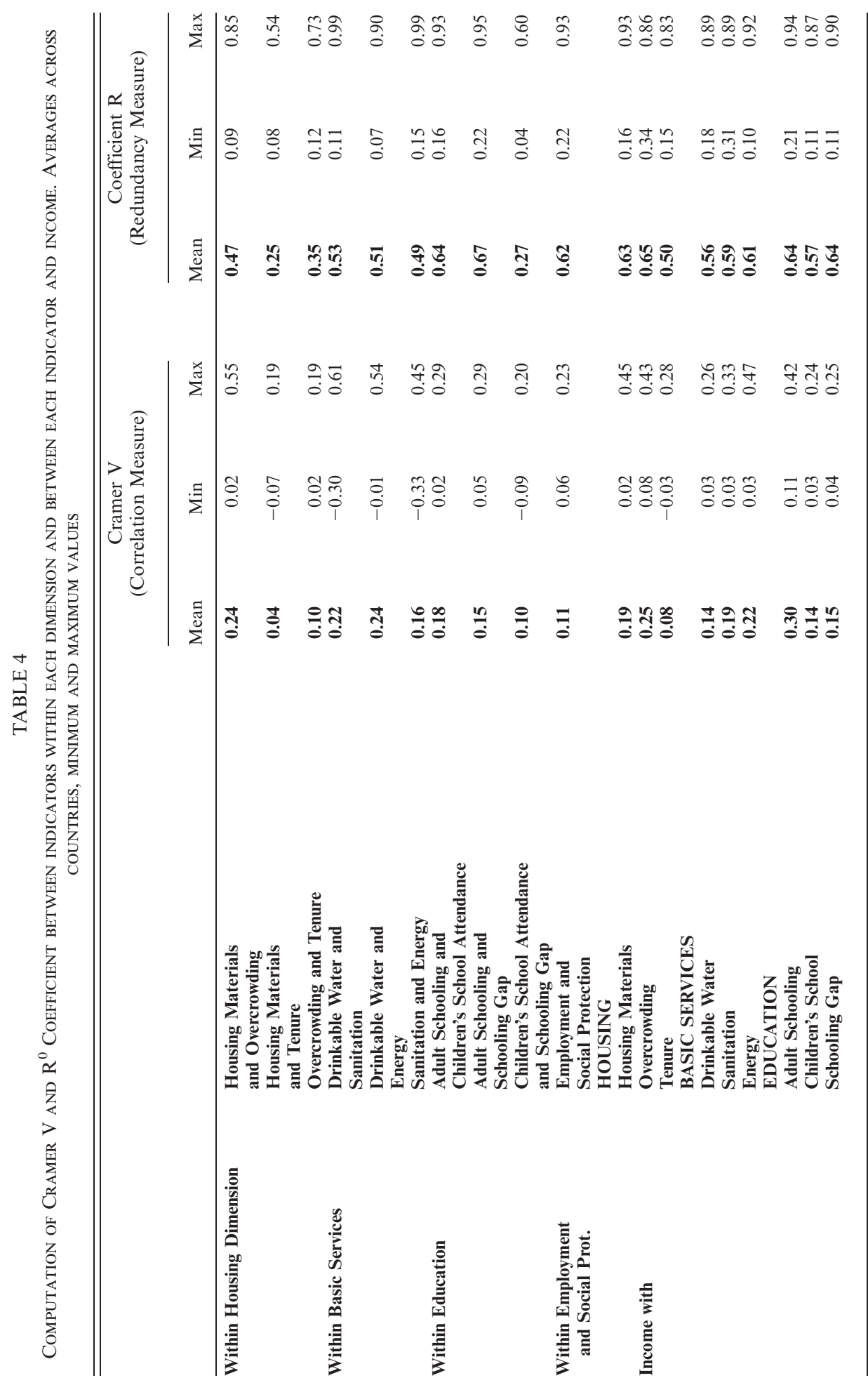

(C) 2016 International Association for Research in Income and Wealth 


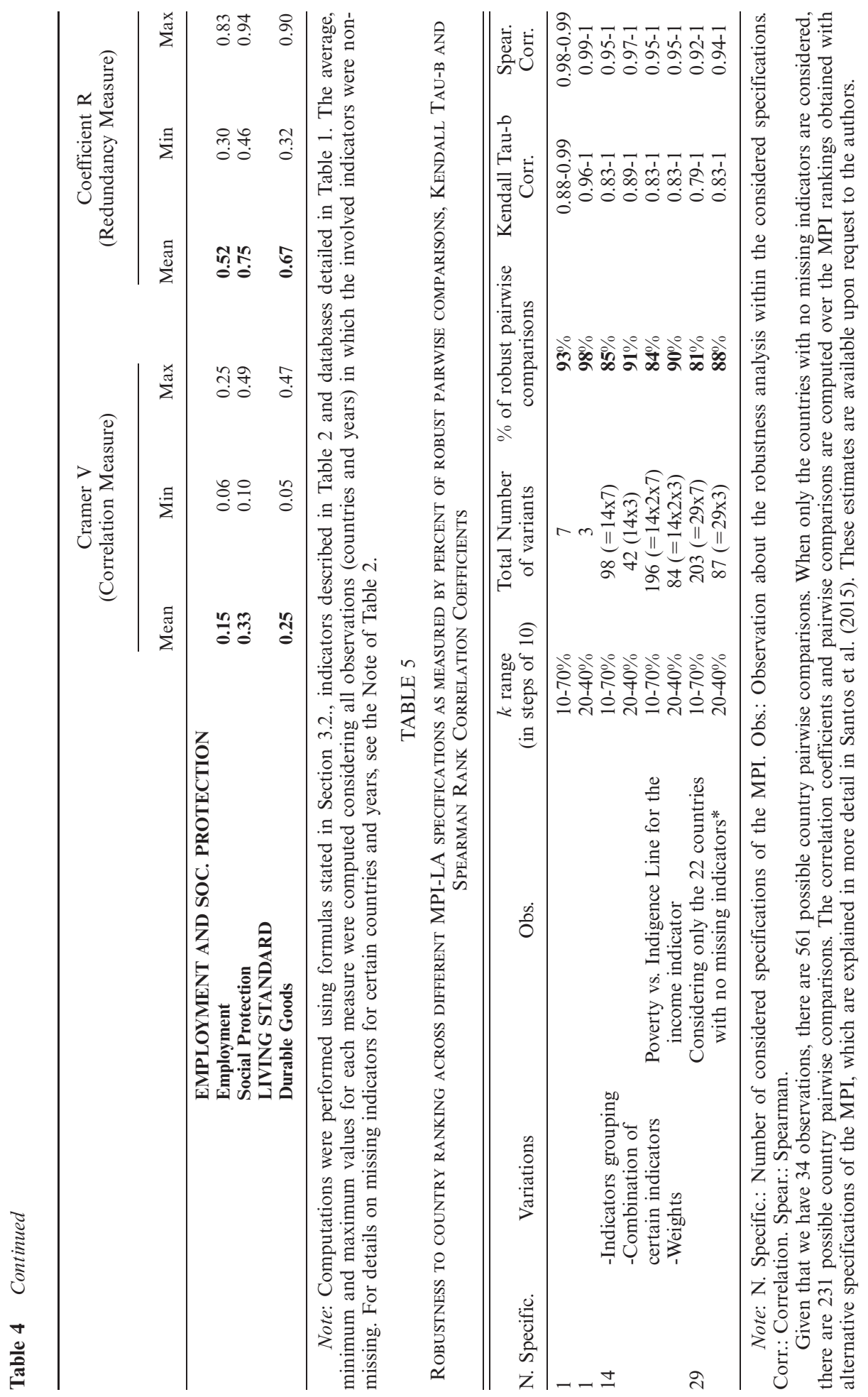

(C) 2016 International Association for Research in Income and Wealth 
will constitute an instrument for informing public policy. As in any poverty measure, there are a number of decisions involved in the construction of the MPI, namely, the selection of indicators, cut-offs, (explicit) weights and the poverty cutoff $k$.

We have performed two types of robustness analysis. In the first place, we evaluated MPI-LA country ranking robustness to changes in MPI's parameters' values. Following Alkire and Santos (2014), we compared every possible pair of countries under alternative specifications. Whenever a country A is poorer than a country B under a particular specification of the MPI, the pair is said to be robust if such relationship holds under a different specification of the MPI. The country ranking is considered to be robust when there is a high proportion of robust pairwise comparisons. We also computed Spearman and Kendall ranking correlation coefficients, which are related instruments of analysis to the pairwise comparisons (see Alkire et al. 2015). Secondly, we evaluated robustness in the identification of the poor under changes in MPI's weighting structure. ${ }^{18}$ Results on each are described in turn.

\section{Robustness in Country Ranking}

We estimated a total of 58 alternative specifications of the MPI-LA, varying one parameter at a time (with respect to the proposed measure) as well as several at the same time, and all of them were estimated for the full range of $k$ poverty cut-offs (from 10 to 100 percent). The 58 alternative specifications involve essentially six types of variations. First, we explored alternative groupings of the indicators into dimensions. ${ }^{19}$ Second, we explored combining related indicators, such as cooking fuel and electricity into single union indicators. Third, we also considered excluding certain indicators, namely household tenure, electricity and cooking fuel. All in all, there are specifications with 11 to 15 indicators, grouped into three to five dimensions. As we primarily follow an equal weighting approach across and within dimensions, alternative numbers of indicators grouped in different ways entail alternative weighting structures. For example, the explicit weight assigned to income ranged from a minimum of 3.7 percent to a maximum of $25 \%$. The weights of the other indicators also vary greatly.

Fourth, we also tried using non-equal weighting structures. Fifth, we estimated most of the different specifications with the income indicator using the total poverty line and-alternatively - the indigence line. Sixth, we tried four alternative definitions of the employment indicator, defining a household deprived in employment if (1) the household head, (2) more than half of its members, (3) half or more of its members, or (4) at least one of its members - correspondingly in each specification - is deprived in employment.

Table 5 presents the country ranking MPI-LA robustness results in a synthetic form. In terms of variation of the poverty cut-off $k$, we consider the relevant range of 10 percent to 70 percent. Note that a poverty cut-off of 10 percent implies being deprived in at least both employment and social protection

\footnotetext{
${ }^{18}$ We thank one of the anonymous referees for suggesting this alternative.

${ }^{19}$ See Santos et al. (2015) for further details.
} 
TABLE 6

Alternative Weighting Structures for testing the SET OF PeOPle identified as Poor

\begin{tabular}{|c|c|c|c|c|}
\hline \multirow[b]{2}{*}{ Dimensions } & \multicolumn{4}{|c|}{ Weights $(\%)$} \\
\hline & $\begin{array}{c}\text { SET 1 } \\
\text { (baseline) }\end{array}$ & SET 2 & SET 3 & SET 4 \\
\hline Housing & 22.2 & 20 & 20 & 23.08 \\
\hline Housing materials & 7.4 & 6.67 & 6.67 & 7.69 \\
\hline People per room & 7.4 & 6.67 & 6.67 & 7.69 \\
\hline Housing tenure & 7.4 & 6.67 & 6.67 & 7.69 \\
\hline Basic Services & 22.2 & 20 & 20 & 23.08 \\
\hline Improved Water Source & 7.4 & 6.67 & 6.67 & 7.69 \\
\hline Improved Sanitation & 7.4 & 6.67 & 6.67 & 7.69 \\
\hline Energy & 7.4 & 6.67 & 6.67 & 7.69 \\
\hline Living Standard & 22.2 & 20 & 20 & 15.38 \\
\hline Monetary Resources & 14.8 & 13.33 & 10.00 & 7.69 \\
\hline Durable Goods & 7.4 & 6.67 & 10.00 & 7.69 \\
\hline Education & 22.2 & 20 & 20 & 23.08 \\
\hline Children's School Attendance & 7.4 & 6.67 & 6.67 & 7.69 \\
\hline Schooling Gap & 7.4 & 6.67 & 6.67 & 7.69 \\
\hline Adult Schooling Achievement & 7.4 & 6.67 & 6.67 & 7.69 \\
\hline Employment and Social Protection & 11.1 & 20 & 20 & 15.38 \\
\hline Employment & 7.4 & 6.67 & 10.00 & 7.69 \\
\hline Health Insurance/Social Protection & 3.7 & 6.67 & 10.00 & 7.69 \\
\hline Social Security & & 6.67 & & \\
\hline
\end{tabular}

Note: Set 1 is the one used in the MPI-LA proposed in this paper.

indicators; in the durable goods indicator or any indicator of housing, services or education - plus one of employment or social protection; or in income alone. At the other extreme, a poverty cut-off of 70 percent demands being deprived at least in any three of the four dimensions that weight 22.22 percent plus in the employment and social protection dimension - admittedly a highly demanding cut-off. At the poverty cut-off of 80 percent poverty estimates decrease dramatically in all countries to 10 percent or less, and in most cases to 5 percent or less. Such a cut-off implies almost an intersection criterion. This makes the country ranking less discriminating, and thus it is not sensible to test for robustness at this cut-off and over.

The proportion of pairwise robust comparisons in each of the tested set of alternative specifications are high, 80 percent or higher, and are even higher within the restricted range of $k$ values of $20-40$ percent. The Kendall and Spearman correlation coefficients are also high.

\section{Robustness in the identification of the poor}

The idea motivating this other robustness analysis it is that even when country rankings are robust to parameters' changes, the set of people identified as poor may vary significantly, which is a very relevant matter when targeting social policy within a country.

We considered in this case four alternative weighting structures, detailed in Table 6. Set 1 is the baseline proposed in this paper. Set 2 differs from the baseline weights in that a) it gives equal weights to the five dimensions (rather than weighting less the social protection and employment one), b) it separates the social 
security indicator from the health insurance one. Set 3 differs from the baseline weights in that it gives equal weights to the five dimensions (rather than weighting less the social protection and employment one) and equal weights within all dimensions (rather than weighting income more than durable goods). Finally, Set 4 differs from Set 1 in that it gives the same weight to all indicators, which means that the living standard dimension and the employment and social protection dimension weight less than the other three dimensions because they only have two indicators each.

It must be noted that using a $k$ cut-off of 25 percent, Set 1 - the baseline - is more demanding than Sets 2 and 3 but less demanding than Set 4. Someone in a household deprived in employment, health insurance and social security (the whole employment and social security dimension) already has a deprivation score of 20 in Set 2 or in Set 3, and any other additional deprivation is enough to be identified as multidimensionally poor. On the contrary this same person requires being additionally income deprived in order to be identified as multidimensionally poor in Set 1, or otherwise to experience any other two additional deprivations in Set 1 or in Set 4 . Set 4 is also more demanding than Set 1 because it requires someone deprived in the living standard dimension to experience in any other two additional deprivations to be identified as poor, whereas in Set 1 any other one is enough to add up to a 25 percent deprivation score. It must be noted that this exercise was performed over the 26 observations with complete indicators of the considered specifications. Lacking one (or more) indicator implies that weights are re-distributed within the dimension making the test to alternative weightings not meaningful.

In Table 7 we present the results of the robustness analysis in terms of the group of people identified as poor under alternative weighting structures. In the first column we present the proportion of multidimensionally poor people using the weights of Set 1, proposed in this paper. The following column reports the proportion of people identified as poor under the four alternative weighting structures detailed in Table 6, a group which may be called the "consistently poor". The last column reports the proportion of people identified as poor under one, two or three of the four alternative weighting structures, but not in the four ones. This group may be called the "inconsistently poor". Countries are ordered from the highest to the lowest proportion as identified by the baseline set of weights.

In Table 7 one can see that only four observations have proportions of 15 to 20 percent of inconsistently poor people (Ecuador 2005 and Paraguay 2011; Dominican Republic 2006 and 2012). The rest has lower values, which suggests that the group of people defined as multidimensionally poor is not highly sensitive to changes in the weighting structure. From the table, one can also notice an inverted-U relationship between the proportion of "inconsistently poor" and the proportion of poor as identified by the baseline set of weights. Countries with lower poverty incidence (say, below 30 percent) and higher poverty incidence (say, above 60 percent), both have low proportions of inconsistently poor people, between 3 percent and 12 percent. This is intuitive: most people in these countries are - correspondingly - either non-poor or poor enough to be identified as poor by any weighting structure. Countries in the mid-range of poverty are the ones with higher levels of inconsistently poor people. 
TABLE 7

RobustNeSS OF MPI-LA TO THE SET OF PEOPLE IDENTIFIED AS POOR UNDER ALTERNATIVE WEIGHTINGS

\begin{tabular}{|c|c|c|c|}
\hline Country and Year & $\begin{array}{l}\text { MPI-LA Poor }{ }^{\mathrm{a}} \\
\text { (Set } 1 \text {, baseline } \\
\text { weights) }\end{array}$ & $\begin{array}{l}\text { Consistently } \\
\text { Poor }^{\mathrm{b}}\end{array}$ & $\begin{array}{c}\text { Inconsistently } \\
\text { Poor }^{\mathrm{c}}\end{array}$ \\
\hline Guatemala 2000 & $79 \%$ & $77 \%$ & $5 \%$ \\
\hline Honduras 2006 & $73 \%$ & $66 \%$ & $12 \%$ \\
\hline Honduras 2010 & $71 \%$ & $65 \%$ & $11 \%$ \\
\hline Guatemala 2006 & $70 \%$ & $68 \%$ & $7 \%$ \\
\hline Paraguay 2005 & $65 \%$ & $59 \%$ & $12 \%$ \\
\hline Peru 2003 & $63 \%$ & $59 \%$ & $9 \%$ \\
\hline Bolivia 2011 & $58 \%$ & $55 \%$ & $10 \%$ \\
\hline El Salvador 2012 & $53 \%$ & $48 \%$ & $12 \%$ \\
\hline El Salvador 2004 & $53 \%$ & $49 \%$ & $10 \%$ \\
\hline Paraguay 2011 & $50 \%$ & $43 \%$ & $15 \%$ \\
\hline Dominican Rep. 2006 & $48 \%$ & $37 \%$ & $20 \%$ \\
\hline Ecuador 2005 & $46 \%$ & $37 \%$ & $17 \%$ \\
\hline Mexico 2004 & $43 \%$ & $38 \%$ & $12 \%$ \\
\hline Colombia 2008 & $41 \%$ & $33 \%$ & $14 \%$ \\
\hline Mexico 2012 & $40 \%$ & $34 \%$ & $12 \%$ \\
\hline Dominican Rep. 2012 & $38 \%$ & $29 \%$ & $19 \%$ \\
\hline Peru 2012 & $37 \%$ & $35 \%$ & $9 \%$ \\
\hline Colombia 2012 & $35 \%$ & $28 \%$ & $13 \%$ \\
\hline Ecuador 2012 & $31 \%$ & $24 \%$ & $14 \%$ \\
\hline Brazil 2005 & $28 \%$ & $20 \%$ & $9 \%$ \\
\hline Costa Rica 2005 & $19 \%$ & $13 \%$ & $8 \%$ \\
\hline Costa Rica 2012 & $15 \%$ & $10 \%$ & $6 \%$ \\
\hline Brazil 2012 & $14 \%$ & $10 \%$ & $5 \%$ \\
\hline Chile 2003 & $13 \%$ & $9 \%$ & $7 \%$ \\
\hline Uruguay 2012 & $9 \%$ & $8 \%$ & $3 \%$ \\
\hline Chile 2011 & $7 \%$ & $3 \%$ & $6 \%$ \\
\hline
\end{tabular}

${ }^{\text {a }}$ The proportion of people identified as poor using the MPI-LA as defined in Table 2 and a $k$ cut-off of $25 \%$.

${ }^{\mathrm{b}}$ The proportion of people identified as poor using the MPI-LA as defined in Table 2 and also identified as poor with an MPI using the indicators defined in Table 2 but weighting structures 2, 3 and 4 defined in Table 6 . In all cases a $k$ cut-off of $25 \%$ was used.

${ }^{\mathrm{c}}$ The proportion of people identified as poor under one, two or three of the four alternative weighting structures defined in Table 6 , but not in the four ones.

In sum, the MPI-LA is highly robust in terms of the poverty orderings across countries and years not only to the $k$ poverty cut-off but also to simultaneous changes in the number and grouping of the considered indicators, the weighting structure, the income deprivation cut-off, and the definition of the employment indicator. This analysis indicates that although there are several normative decisions involved in the construction of the proposed MPI-LA, these do not critically affect the poverty ranking obtained. Also, the group identified as poor is quite stable to plausible changes in the weighting structure. Thus, the MPI-LA seems to be a solid instrument for informing policy both across and within countries.

\section{Results}

Full estimation results are presented as Supplementary Data. Table S.1 presents the multidimensional poverty index or adjusted headcount ratio MPI- 


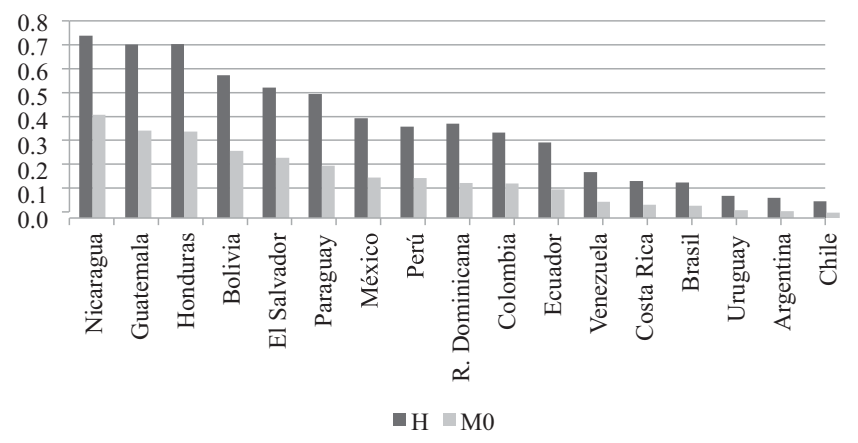

Figure 1. Multidimensional Headcount Ratio (H) and Adjusted Multidimensional Headcount Ratio (M0) according to MPI-LA ca. 2012

Note: Estimations used to construct this figure can be found in Table S.1 of Supplementary Data and were performed using the MPI-LA specification detailed in Table 2, a $k$ cut-off of $25 \%$ and databases specified in Table 1.

LA and its composing sub-indices: incidence $(H)$ and intensity $(A)$. For each, the upper and lower bound estimates, as well as the standard errors, are presented - all obtained via bootstrap. ${ }^{20}$ It also presents the censored headcount ratios of each composing indicator, as well as their corresponding contributions, for each country at both points in time. Tables S.2 and S.3 present the MPI, $H$ and $A$, censored headcount ratios and contributions for urban and rural areas.

\subsection{Aggregate MPI-LA Estimates: Incidence and Intensity}

Figure 1 presents $\mathrm{H}$ and $M_{0}$ in the specified MPI-LA for the 17 countries in the final year of observation, around 2012. ${ }^{21}$ Bootstrapped confidence intervals suggest that the estimates for each country are highly reliable with very small standard errors (see Table S.1).

The graph suggests that there is great variability in the incidence of poverty in the region: while in the Southern cone only one in ten people are multidimensionally poor, in Central America the proportion is seven in ten. The regional incidence of multidimensional poverty, obtained as a population-weighted average of country-incidences, is 28 percent, suggesting that around 159.224 million people

\footnotetext{
${ }^{20}$ For each country we performed 1000 replications and created the bootstrap 95 percent confidence intervals and standard errors. We could not consider the complex survey design because the strata and cluster variables are in general not provided in the datasets.

${ }^{21}$ Results presented here for the year 2012 in Argentina were computed using ECLAC poverty line which is updated on the basis of official levels of inflation. Considering that inflation is underestimated for that year, we performed an alternative estimation that uses a poverty line updated according to the average inflation from several provinces. This yields an augmented income poverty cut-off that is approximately twice the original poverty line. Using this augmented and arguably more accurate income poverty cut-off, we find $M_{0}$ to be 0.055 (vs. 0.028 obtained with the original PL), $H$ to be 15 percent (vs. 8 percent obtained with the original PL), and $A 37$ percent (vs. 35 percent obtained with the original PL). Clearly, these different estimates affect the conclusion on poverty reduction in Argentina.
} 
are multidimensionally poor using 2012 population estimates. ${ }^{22}$ This incidence is 1.86 times higher than the regional incidence of acute poverty estimated in 2010 using the global MPI (Alkire and Santos, 2014).

In line with international evidence (Alkire and Santos, 2010, 2014), the average proportion of deprivations suffered by the poor population $(A)$ in Latin America is larger in countries with higher poverty rates. In countries with the highest poverty rates, the average percentage of deprivations exceeds 45 percent, which means that - on average - the poor are deprived in over two full dimensions (or its equivalent), whereas in countries with the lowest headcount ratios the percentage is below 36 percent, the equivalent of 1.6 dimensions. Note that, by definition, the minimum $A$ value is 25 percent, as this is the poverty cut-off $k$.

\subsection{Poverty in Rural vs. Urban Areas}

Multidimensional poverty is more severe in rural areas, another result in line with global and regional multidimensional poverty evidence (Santos et al. 2010; ECLAC, 2013; Alkire and Santos, 2014). The ratio between rural and urban MPI-LA averages 2.4 times, with Uruguay being the only case where the ratio is close to 1.0 and Peru the only case where the ratio exceeds 4.0 times. In the 13 remaining countries, ${ }^{23}$ the ratio varies between 1.8 and 3.3 times. Noteworthy, a person living in a rural area is not only much more likely to be poor, but, also, the poor experience on average a higher number of deprivations.

\subsection{Changes in Poverty Over Time}

All but one country in the region (El Salvador) experienced statistically significant reductions in their multidimensional poverty levels between the two observed points in time (the first around 2005 and the final around 2012). Hypothesis tests were performed using standard errors obtained with the bootstrap method. The reduction in MPI-LA that each country experienced was a consequence of statistically significant reductions in both incidence and intensity. In this respect it is worth emphasizing the important reductions in intensity verified by Peru and Bolivia.

In Figure 2 we depict annualized relative (Panel A) and absolute (Panel B) reductions in the MPI-LA against initial MPI levels. It can be seen that the less poor countries were the ones achieving higher relative reductions. The largest is found in Argentina ( -18 percent per year), ${ }^{24}$ followed by Uruguay ( -11 percent), Brazil ( -10 percent) and Chile ( -9 percent), countries where poverty was halved during that period. On the other hand, the smallest changes are found in Honduras, Mexico, and Nicaragua, where poverty fell less than 2 percent per year. An opposite though less strong pattern is found in terms of the absolute change.

\footnotetext{
${ }^{22}$ Population estimates correspond to Centro Latinoamericano y Caribeño de Demografía (CELADE) available at $\mathrm{http}$ ://interwp.cepal.org/sisgen/ConsultaIntegrada.asp?idIndicador $=1$ \&idioma $=$ e.

${ }^{23}$ Rural poverty could not be estimated for Argentina and Venezuela due to lack of data.

${ }^{24}$ With the alternative estimates for Argentina in 2012 , the annualized rate of poverty reduction is much lower and similar to that of Uruguay at 11 percent.
} 

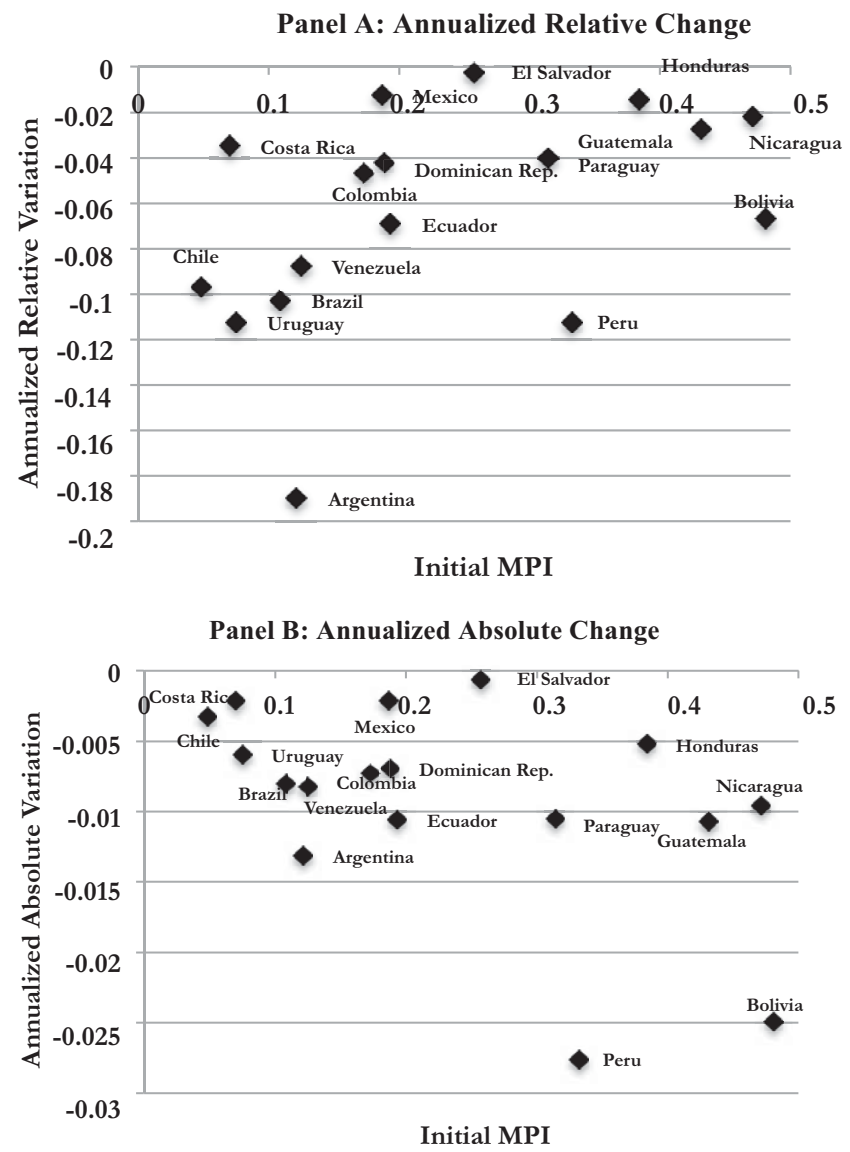

Figure 2. Relative and absolute annualized reductions in the MPI-LA vs. initial MPI-LA level

Note: Absolute and relative annual variations were computed using MPI-LA estimates reported in Table S.1 of Supplementary Data. Such estimates were performed with the MPI-LA specification detailed in Table 2, a $k$ cut-off of 25 and databases listed in Table 1.

\subsection{Multidimensional vs. Income Poverty}

Figure 3 compares our results with income poverty figures using ECLAC poverty lines. Both measures are closely correlated-as Panel A shows. This was expected as income is included in the MPI. However, there are differences in the headcount ratios of income poverty and the MPI poor, as can be seen in Panel B. The MPI headcount ratios fall below the income poverty rates in six countries, while the contrary happens in 11 countries. In Bolivia, Guatemala, and Nicaragua the multidimensional index is more than 15 percentage points above the monetary poverty rate, while in Peru the difference is 11 percentage points.

In any case, the similarity of poverty rates should not be understood as if both methods are identifying the same population as poor. We computed for each country and year the proportion of people who are income poor but not MPI poor and vice versa. This exercise is similar in spirit to the bidimensional method, 

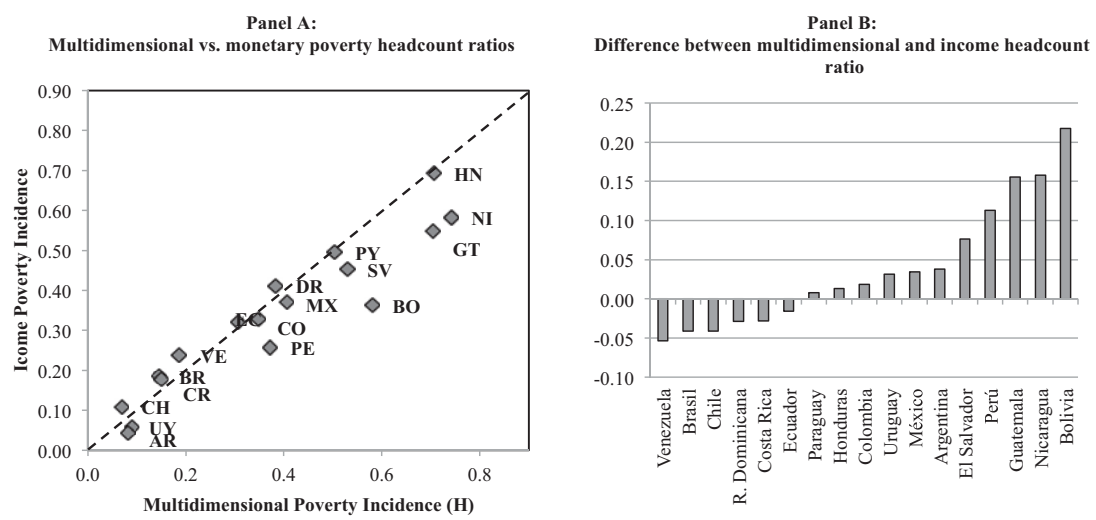

Figure 3. Multidimensional vs. income poverty headcount ratios, ca. 2012

Note: Multidimensional poverty estimates to construct this figure can be found in Table S. 1 of Supplementary Data, which were performed using the MPI-LA specification detailed in Table 2, a $k$ cut-off of $25 \%$ and databases specified in Table 1 . Income poverty estimates correspond to ECLAC's estimates of the proportion of income poor people using the total poverty line, which are annually reported in Social Panorama of Latin America as well as on-line at http://estadisticas.cepal. org/cepalstat/WEB_CEPALSTAT/buscador.asp?idioma=e\&string_busqueda=pobreza. The exact value of the total poverty line used for each country and year can also be consulted on-line.

AR: Argentina, BO: Bolivia, BR: Brazil, CH: Chile, CO: Colombia, CR: Costa Rica, DR: Dominican Republic, EC; Ecuador, GT: Guatemala, HN: Honduras, MX: México, NI: Nicaragua, PY: Paraguay, PE: Perú, SV; El Salvador, UY: Uruguay, VE: Venezuela.

although with the obvious difference that the MPI includes income. ${ }^{25}$ We find that for the $k=25 \%$ poverty cut-off value, the proportion of those who are not MPI poor but are income poor ranges from a maximum of 23 percent in Bolivia in 2011 to a minimum of 1 percent in Chile in 2011, the simple average across countries is 9 percent. The proportion of people who are income poor but not MPI poor ranges from a maximum of 11 percent in the case of the Dominican Republic to virtually zero in the case of Argentina, the simple average being 5 percent. When the proportion of the population in each of the mismatches is seen as a proportion of the poor in each method, the discrepancies look quite higher. For example, in the case of Bolivia, it means that almost 40 percent of the multidimensionally poor are not income poor, and in the case of the Dominican Republic it means that 27 percent of the income poor are not multidimensionally poor. We also find, in line with findings in Santos, (2013) that the higher the incidence of multidimensional poverty, the higher the proportion of people who are multidimensionally poor yet not income poor and the lower the proportion of the converse mismatch. The same relationship is verified with income poverty.

In sum, while the size of the mismatches between the income and the MPI poor is not massive, evidence suggests that the MPI is useful to identify population that suffers from multiple deprivations and may be considered poor even if their incomes are not below the poverty line. This reinforces the relevance of this instrument for public policy challenges.

\footnotetext{
${ }^{25}$ See Santos (2013) for a description of the relationship between the deprivation cut-off $k$ and the discrepancies when income is an indicator in an AF measure.
} 


\subsection{Composition of Poverty}

Among the five dimensions considered by the index, the dimension of living standard stands out as the largest contributor. On average it represents a third of total deprivations. Within this dimension, most of the contribution is made by the indicator of income deprivation, with the indicator of durable goods representing less than 12 percent of total poverty in all countries. On average, the contribution of the remaining four dimensions is similar, although education tends to have a larger contribution than housing and basic services in most countries. Within education, years of schooling is the indicator that contributes the most, usually representing half or more of the dimension.

To have a sense of absolute deprivation levels in each indicator, Table S.1 in the Supplementary Data presents the censored headcount ratios, namely, the proportion of people identified as multidimensionally poor who experience deprivation in each indicator. We do not delve into the numbers here for the sake of brevity, but further details can be found in Santos et al. (2015).

Comparing the contribution of the different dimensions to overall poverty with the level of poverty, we find that the contribution of the employment and social protection dimensions as well as that of the living standard dimension decreases with the MPI. On the other hand, the dimensions of basic services and housing show the opposite pattern, contributing more to multidimensional poverty in countries with higher poverty levels. The education dimension does not show a clear correlation pattern with the level of poverty.

The contribution of each dimension to total poverty is different in urban and rural areas. One emerging pattern is that in all 15 countries with data for both areas, the living standard dimension has a larger weight in urban areas than in rural areas. Also, when comparing the contribution of the different dimensions to the MPI in 2005 with that in 2012, we find it was very similar in both years, with only some specific cases of significant changes which are discussed in more detail in Santos et al. (2015).

\section{Concluding Remarks}

In this paper we have proposed a Multidimensional Poverty Index for the Latin American region. It is composed of 13 indicators grouped into five dimensions: housing, comprising housing materials, rooms per person and housing tenure; basic services, comprising water, sanitation and energy; education, comprising adult school achievement, children's school attendance and schooling gap; employment and social protection; and living standards, comprising income, and durable goods. Employment and social protection have weights of 11.11 percent, with employment being weighted as twice social security, and the other four have weights of 22.22 percent, with equal weighting within dimensions except for the case of living standard, in which income is weighted as twice durable goods. We consider someone to be multidimensionally poor if she is deprived in 25 percent or more of the weighted indicators, meaning that a person is required to be deprived at least in the equivalent of a full dimension of the four with equal weights, plus something else. 
We estimated poverty for 17 countries at two points in time, one around 2005 and the other around 2012. Considering the final year of observation for each country, we find poverty to be highest in three Central American countries: Guatemala, Honduras and Nicaragua, and lowest in three Southern cone countries: Uruguay, Argentina and Chile. Overall, we estimate that about 28 percent of people in the region are multidimensionally poor, which means 159.224 million people using 2012 population estimates.

An encouraging result is that we find a statistically significant reduction in poverty between these two points in all countries except for El Salvador, with significant reductions of both incidence and intensity. Annual relative reductions were bigger in less poor countries, but there were important reductions in absolute levels in poorer countries. However, important disparities between rural and urban areas of each country remain, these being particularly big in Peru, Chile, Ecuador, Bolivia, and Paraguay.

Among the components of multidimensional poverty, living standards, led by income deprivation, emerge as a significant contributor to overall poverty, accounting - on average - for 30 percent of total poverty. The contribution of the remaining four dimensions is fairly similar, although there are variations across countries. The relative contribution of deprivations in employment and social protection as well as in living standards tend to be higher in less poor countries, whereas the relative contribution of deprivations in housing and basic services tends to be higher in poorer countries. In line with this, the living standard dimension has a larger contribution in urban areas than in rural areas whereas the opposite holds for the housing dimension.

When the MPI-LA is compared with income poverty, we find the mismatches in the population considered poor by each method to be not marginal, suggesting that the MPI-LA is a more accurate instrument to identify the poor than each method separately.

The proposed MPI-LA seems to capture relatively well the state of povertywithin the data constraints - as suggested by exploratory factor analysis. It also seems to comply with some degree of parsimony, as suggested by correlation and redundancy measures. Finally, it is highly robust to changes in weighting structures, the poverty cut-off and the indicators used, as well as to the monetary deprivation cut-off. It certainly has limitations, which can be gradually overcome by improvements in data collection.

\section{REFERENCES}

Alcock, P., Understanding Poverty, Third Edition, Palgrave Macmillan, Basingstoke 2006.

Alkire, S. and P. Ballon, "Understanding Association across Deprivation Indicators in Multidimensional Poverty," Paper presented at the Research Workshop on Dynamic Comparisons between Multidimensional Poverty and Monetary Poverty, Oxford Poverty and Human Development Initiative (OPHI), University of Oxford, 2012.

Alkire, S. and J. E. Foster, "Counting and Multidimensional Poverty Measurement," Journal of Public Economics, 95, 476-87, 2011.

Alkire, S. and M. E. Santos, "Acute Multidimensional Poverty: A New Index for Developing Countries," OPHI Working Paper 38, University of Oxford, 2010.

— mensional Poverty Index," World Development, 52, 71-91, 2014. 
Alkire, S., M. Apablaza, and E. Jung, "Multidimensional Poverty Measurement for EU-SILC Countries," OPHI Research in Progress 36c, University of Oxford, 2014.

Alkire, S. et al. Multidimensional Poverty Measurement and Analysis, Oxford University Press, Oxford, 2015.

Altimir, O., La Dimensión de la Pobreza en América Latina, Cuadernos de la Cepal, Naciones Unidas, Santiago, 1979.

Angulo, R., B. Y. Díaz, and R. Pardo Pinzón, "A Counting Multidimensional Poverty Index in Public Policy Context: The Case of Colombia,” OPHI Working Paper 62, University of Oxford, Oxford, 2013.

Attanasio, O. and M. Székely, Portrait of the Poor: An Assets-Based Approach, Johns Hopkins University Press, Baltimore, 2001.

Atkinson, A.B. et al., Social Indicators, The EU and Social Inclusion, Oxford University Press, Oxford, 2002.

Battiston, D. et al., "Income and Beyond: Multidimensional Poverty in Six Latin American Countries," Social Indicators Research, 112, 291-314, 2012.

Bazoglu, N. et al., Monitoring Security of Tenure in Cities: People, Land and Policies, United Nations Human Settlements Programme (UN-Habitat), Nairobi, 2011.

Beccaria, L. and A. Minujín, "Métodos Alternativos para medir la Evolución del Tamaño de la Pobreza," Documentos de Trabajo, 6, Instituto Nacional de Estadística y Censos (INDEC), Buenos Aires, 1985.

Birdsall, N. and C. Graham (eds), New Markets, New Opportunities? Economic and Social Mobility in a Changing World, Brookings Institution Press, Washington DC, 2000.

Boltvinik, J., "El Método de Medición Integrada de la Pobreza. Una Propuesta para su Desarrollo," Comercio Exterior, 42, 354-65, 1992.

Borda, D. and F. Masi, Pobreza, Desigualdad y Politica Social en América Latina, North-South Center Press, University of Miami, Coral Gables, 2001.

Bradshaw, J. and N. Finch, "Overlaps in Dimensions of Poverty," Journal of Social Policy, 32, 513-25, 2003.

Callan, T., B. Nolan, and C. Whelan, "Resources, Deprivation and the Measurement of Poverty," Journal of Social Policy, 22, 141-72, 1993.

Castillo, A., R. and F. J. Perez, "Medición de la Pobreza Multidimensional en Ecuador," INEC (Instituto Nacional de Estadísticas y Censos), Ecuador, 2015. http://www.ecuadorencifras.gob.ec/documentos/web-inec/Sitios/Pobreza_Multidimensional/assets/ipm-metodologia-oficial.pdf. Accessed February 2016.

Cardoso, E. and A. Helwege, "Below the Line: Poverty in Latin America," World Development, 20, 1937, 1992.

CONEVAL (Consejo Nacional de Evaluación de la Política de Desarrollo Social de México), Informe de pobreza multidimensional en México 2008, Mexico, 2010.

Costello, A. B. and J. W. Osborne, "Best Practices in Exploratory Factor Analysis: Four Recommendations for Getting the Most from your Analysis," Practical Assessment, Research and Evaluation, $10,1-9,2005$.

Deaton, A., The Analysis of Household Surveys: A Microeconometric Approach to Development Policy, John Hopkins University Press, Baltimore, MD, 1997.

Decanq, K. and M. A. Lugo, "Weights in Multidimensional Indices of Well-Being: An Overview," Econometric Reviews, 32, 7-34, 2012.

Desai, M. and A. Shah, "An Econometric Approach to the Measurement of Poverty," Oxford Economic Papers, 40, 505-22, 1998.

ECLAC, Social Panorama of Latin America, 2013 (LC/G.2580-P), Economic Commission for Latin America and Caribbean (ECLAC), Santiago, 2013.

, Time for Equality: Closing Gaps, Opening Trails, The Thirty-third Session of ECLA, LC/G.2432(SES.33/3), Economic Commission for Latin America and Caribbean (ECLAC), Santiago, 2010.

ECOSOC, Progress towards Education for All in Latin America and the Caribbean. Regional Preparatory Meeting 2011, United Nations Economic and Social Council. Annual Ministerial Review, Regional Bureau of Education for Latin America and the Caribbean OREALC/UNESCO, Santiago, 2011.

Ferreira, F. et al., "Economic Mobility and the Rise of the Latin American Middle Class," World Bank Latin American and Caribbean Studies No. 73823, Washington DC, 2012.

Furtado, C., Desarrollo y Subdesarrollo, Buenos Aires, 1961.

Glindling, T. H., "Poverty in Latin America," Latin American Research Review, 40, 207-22, 2005.

Gobierno de El Salvador, "Medición multidimensional de la pobreza en El Salvador." San Salvador: Secretaría Técnica y de Planificación de la Presidencia y Ministerio de Economía, a través de la Dirección General de Estadística y Censos, 2015. http://www.secretariatecnica.gob.sv/gobierno-oficializa-implementacion-de-medicion-de-la-pobreza-multidimensional. Accessed February 2016.

Instituto Nacional de Estadísticas y Censos (INDEC), La Pobreza en la Argentina, Indicadores de Necesidades Básicas Insatisfechas a Partir de los Datos del Censo Nacional de Población y Vivienda 1980, Presidencia de la Nación, Secretaría de Planificación, 1984. 
Instituto Nacional de Estadísticas y Censos (INEC), Indice de Pobreza Multidimensional. Metodología, Costa Rica, 2015. http://www.inec.go.cr/sites/default/files/documentos/pobreza_y_presupuesto_ de_hogares/pobreza/metodologias/mepobrezaenaho2015-01.pdf. Accessed January 2016.

Kaztman, R., "La Heterogeneidad de la pobreza: El caso de Montevideo," Revista de la Cepal, 37, $141-52,1989$.

—_ "La dimensión espacial de la cohesión social en América Latina," in La Cohesión Social en América Latina. Una Revisión de Conceptos, Marcos de Referencia e Indicadores, Documentos de Proyecto (LC/G.2420), Comisión Económica para América Latina y el Caribe (CEPAL), Santiago, 2010.

- "Infancia en América Latina: Privaciones habitacionales y desarrollo de capital humano," (LC/W.431), Comisión Económica para América Latina y el Caribe (CEPAL)/Fondo de las Naciones Unidas para la Infancia (UNICEF), Santiago, 2011.

Levy, S., "Latin America's Social Policy Challenge: Education, Social Insurance, Redistribution," Journal of Economic Perspectives, 27, 193-218, 2013.

Lopez-Calva, L. F. and N. C. Lustig, Declining Inequality in Latin America: A Decade of Progress? United Nations Development Program (UNDP), 2010.

Lopez, R. and A. Valdés, Rural Poverty in Latin America, St. Martin's Press, New York, 2000.

Mack, J. and S. Lansley, Poor Britain. Allen and Unwin, London, 1985.

Marinakis, A., "Non-Compliance with Minimum Wage Laws in Latin America: The Importance of Institutional Factors," International Labour Review, 155, 133-56, 2016.

Ministerio de Desarrollo Social de Chile, CASEN 2013: Situación de la Pobreza en Chile. Presentacion de la Nueva Metodologia de Medicion de la Pobreza y Sintesis de los Principales Resultados, 2015.

Narayan, D., R. Chambers, M. K. Shah, and P. Petesch, Voices of the Poor: Crying Out for Change, World Bank, Washington, DC, 2000.

Nolan, B. and C. Whelan, Resources, Deprivation and Poverty, Oxford University Press, Oxford, 1996.

- Poverty and Deprivation in Europe, Oxford University Press, Oxford, 2011.

Ocampo, J. A. and J. Ros, The Oxford Handbook of Latin American Economics, Oxford University Press, Oxford, 2012.

Papadopoulos, T. and R. V. Leyer, "Two Decades of Social Investment in Latin America: Outcomes, Shortcomings and Achievements of Conditional Cash Transfers," Social Policy and Society, 15, 435-49, 2016.

Pinto, A., "Concentración del progreso técnico y de sus frutos en el desarrollo de América Latina," El Trimestre Económico, 32, 3-69, 1965.

Roche, J. M. and M. E. Santos, "In Search of a Multidimensional Poverty Index for Latin America," Paper presented at 5th ECINEQ Meeting, 2-24 July 2013, Bari, Italy, 2013.

Santos, M. E., "Tracking Poverty Reduction in Bhutan: Income Deprivation alongside Deprivation in Other Sources of Happiness," Social Indicators Research, 112, 259-90, 2013.

_ Forward," OPHI Working Paper 66, University of Oxford, 2014.

- et al., "Refining the Basic Needs Approach: A Multidimensional Analysis of Poverty in Latin America," Research on Economic Inequality, Vol. 18: Studies in Applied Welfare Analysis: Papers from the Third ECINEQ Meeting, 1-29, Emerald, Bingley, 2010.

Santos, M.E. et al., "A Multidimensional Poverty Index for Latin America," OPHI Working Paper 79, University of Oxford, 2015.

Sen, A. K., The Idea of Justice, Penguin, Harmonsworth, 2009.

Sunkel, O., El Subdesarrollo Latinoamericano y la Teoría del Desarrollo, Siglo XXI, Mexico, 1970.

UNDP, The Real Wealth of Nations: Pathways to Human Development. Human Development Report 2010, UNDP, New York, 2010.

, A Million Voices: The World We Want: A Sustainable Future with Dignity for All, UNDP, New York, 2013.

UNESCO, 2012 EFA Global Monitoring Report. Youth and Skills: Putting Education to Work, UNESCO, Paris, 2012.

Villatoro, P., "Hacia la Ampliación del Segundo Objetivo del Milenio: Una Propuesta para América Latina y el Caribe," Serie Políticas Sociales 132 (LC/L.2712-P), Comisión Económica para América Latina y el Caribe (CEPAL), Santiago, 2007.

Whelan, C., R. Layte, and B. Maître, "Understanding the Mismatch between Income Poverty and Deprivation: A Dynamic Comparative Analysis,” European Sociological Review, 20, 287-302, 2004. 